\title{
A CENTRALIDADE DO POP NA MÍDIA: O SUJEITO CONTEMPORÂNEO NA LITERATURA DE NICK HORNBY
}

Thiago Pereira Alberto*

RESUMO: O artigo pretende analisar a centralidade do pop na sociedade contemporânea, especificamente na obra do escritor britânico Nick Hornby. Construindo suas narrativas pautadas justamente nestes sujeitos midiatizados e identificados com essa idéia de cultura pop, Hornby inscreve seus personagens como narradores do nosso tempo, em que a música, o cinema, a televisão, entre outros elementos da chamada indústria do entretenimento, servem de aporte para a construção do self. Portanto, a literatura de Hornby situa seus leitores no contexto da sociedade atual compartilhando signos comuns da mídia e conseguindo com isso mapear algumas possibilidades de como poderíamos pensar o pop atuando como uma lógica de subjetivações nos sujeitos contemporâneos.

PALAVRAS-CHAVE: 1. Nick Hornby 2. Literatura 3. Pop. *thiagopereiraalberto@gmail.com Mestrando pelo programa de Pós- Graduação em Comunicação Social da PUC-MG.

ABSTRACT: The article analyzes the centrality of pop in contemporary society, specifically in the work of British writer Nick Hornby. Building their narratives precisely in subjetcs guided by media and identified with this idea of pop culture, Hornby inscribes his characters as storytellers of our time, where music, film, television, and other elements of the so called entertainment industry, serve as an input for the construction of self. Therefore, Hornby's literature places its readers in the context of modern society, sharing common signs and as a consequence, being able to map some possibilities of how we think the pop acting as a logic of subjectivation in contemporary subjects.

KEYWORDS: 1. Nick Hornby 2. Literature 3. Pop. 


\section{INTRODUÇÃO}

Se pudermos pensar o pop como um repertório variado de elementos da sociedade de consumo que potencializa uma lógica de subjetivação na contemporaneidade, o escritor britânico Nick Hornby se firma como um dos narradores mais afinados com nossos tempos. É justamente essa exposição, essa centralidade ocupada pelo pop contemporâneo que vai influenciar boa parte da produção autoral de escritores como Hornby, aliada a uma necessidade de narrar o próprio tempo e a tentativa de retratar individualidades a partir de preferências entre os signos comuns oferecidos pela indústria do entretenimento - quando estes acabam atuando como possíveis espaços de representação e reconhecimento. Como aponta Cruz

[...] o fenômeno pop pode ser compreendido como uma visão de mundo, uma atitude perante a vida, que engloba todas as artes (a música, a literatura, o teatro, a pintura, a escultura e o próprio cinema) e um modus vivendi delimitado historicamente, mas com repercussões até hoje. O pop é um estilo que se propôs como anti-estilo, em uma tentativa de interpretar a modernidade e de inaugurá-la efetivamente no nível comportamental.

1. CRUZ. O pop: literatura, mídia e outras artes, p. 46 . prazeres e identidades, como apontou Kellner (2001) a respeito da cultura das mídias; e é certamente um dos motes da produção literária de Nick Hornby. Na maior parte de sua obra é possível capturar elementos da cultura pop como essenciais para a formatação de suas narrativas e personagens, e muito em função disto ele foi laureado por mídia e público a partir dos anos 90 como um dos maiores representantes de uma possível literatura pop contemporânea.

A literatura de Hornby (popular, espirituosa, consumível e juvenil) usualmente rotulada como pop, possui os fundamentos dessa arte, seja na composição do cotidiano narrado pelas referências à cultura midiática tomada como um conjunto de "objetos achados", usualmente desprezados pela alta cultura; seja pelo seu imediatismo, como ficção de traço hábil oportunamente oferecida ao leitor contemporâneo.

Nascido em 1957, em Surrey, nos arredores de Londres, Hornby é assumidamente fruto de uma geração de escritores ingleses que, como definiu seu contemporâneo e também escritor pop britânico Tony Parsons, foi completamente afetada pelas discussões a respeito da importância da presença massiva da cultura pop na segunda metade do século passado:
2. SERELLE. Sujeito e vida midiatizada: considerações sobre a ficção de Nick Hornby, p. 130.
Esse nível comportamental ao qual se refere Cruz também nos inspira a pensar o pop como um produtor de significados,
EM TESE

BELO HORIZONTE

v. 19

N. 1

JAN.-ABR. 2013

ALBERTO. A centralidade do pop na mídia: o sujeito contemporâneo [...]

P. $112-125$ 
3. PARSONS. Disparos no front da cultura pop, p. 11.

4. HORNBY. Nick Hornby's official site.
Comecei na música e para alguém da minha geração sortuda-bebê quando Elvis vestia 38, criança durante a Beatlemania, adolescente quando Bowie começou a fazer sucesso, jovem durante o movimento punk - a música sempre vai ser importante. Nasci na época certa. Se tivesse nascido dez anos antes ou dez anos depois, sem dúvida nenhuma a esta altura eu estaria implorando para entrar na imprensa automobilística. ${ }^{3}$

Hornby se estabeleceu como professor de inglês e decidiu escrever seus próprios romances, no final da década de 80 . Segundo ele,

[...] tudo mudou quando li autores como Anne Tyler, Raymond Carver, Richard Ford, e Lorrie Moore, [...] a voz, o tom, a simplicidade, o humor e a alma [...]. Todas as coisas que eu percebia que pareciam faltar na ficção contemporânea britânica. Foi aí que decidi o que queria fazer (2011a). ${ }^{4}$

Mas é notável, na obra de Hornby - assim como em autores que ele se diz influenciado como a norte-americana Anne Tyler -, que essa busca por "humor" ou "simplicidade", entre outras características apontadas por ele, se aproxima da narrativa realista romanesca, estabelecida no século XIX Esta simplicidade parece se conectar em sua obra no sentido de representar temas e personagens ordinários, do cotidiano, com os quais tanto ele como autor quanto seus supostos leitores pudessem criar conexões e paralelos imediatos, códigos de reconhecimento.

No caso de Hornby, é através de suas narrativas que ele parece devolver o que nos afeta internamente, através da atuação do que vem de fora (via cultura midiatizada) sobre nós. O que ele aparentemente indica é que somos sujeitos inscritos nas coisas que nos cercam, e, se verificarmos que o grande cimento social da contemporaneidade é a mídia, o que editamos dela como campo de interesse é também parte fundamental do que somos, do que nos molda e constitui. Esse recorte é uma possibilidade de situar o pop e de como podemos ser reconhecidos (e nos reconhecermos) e sermos representados por ele.

A centralidade do pop em nossa cultura hoje é aparente em diversos tentáculos da mídia: seja na música, na televisão, no cinema, na publicidade. E a linguagem pop - imediata, consumível, cotidiana - está nestas mesmas mídias como algo natural, indissociável. Possivelmente porque nos comunicamos através dela, criamos campos de referência e de representação a partir do que consumimos e nos identificamos. Destas formas derivadas da cultura da mídia, parecem emergir sujeitos inscritos no pop, que são posteriormente refletidos na própria mídia, como a obra de Hornby. 


\section{LITERATURA INGLESA E ESTUDOS CULTURAIS: UM}

\section{CONTEXTO HISTÓRICO}

Hornby faz parte de um grupo de escritores contemporâneos que viveram, na juventude, uma época de grande efervescência da cultura popular britânica, acompanhando a criação de verdadeiros ícones de várias áreas, do esporte à moda, da música ao cinema pós anos 1960 . No campo da literatura, a Inglaterra vivia um período de grandes mudanças, muitas orientadas no sentido de desmontar o cânone literário, expresso no que foi chamado de DWEM (Dead White European Male), os autores clássicos europeus, masculinos e brancos. Como aponta Peter Widdowson, entrava em pauta o projeto pós-colonialista na literatura inglesa, que buscava tanto articular as experiências de colonizados antes sem voz, como explorar hibridações possíveis destes mesmos sujeitos, jogando luz sobre a obra de autores de diferentes raças /etnias e gêneros.

Expressivo reflexo desta discussão foram os questionamentos do estudo de "Inglês" (ou "Literatura Inglesa") já que ela atuava como a disciplina responsável pela manutenção do cânone, pensando este como algo "natural e não dado" ${ }^{\text {, }}$ e que não representava outras formas de produção textual (como biografias, jornalismo, músicas). O grande veículo de análise destas novas possibilidades foram os autores dos Estudos Culturais, como Raymond Williams e Stuart Hall, que sugeriam os estudos culturais não como "uma nova disciplina, mas uma nova mentalidade" ${ }^{\text {, }}$ onde o foco de interesse estaria não apenas na literatura, mas na interdisciplinaridade entre todas as formas de produção e representação cultura - e centralmente na cultura popular. O texto canônico e seu status se tornam motivo de análises profundas:

"Historiadores iriam perguntar: por que Rei Lear é leitura essencial para um estudo do início de século XVII na Inglaterra, por que isto é mais importante do que um sermão contemporâneo; o que o torna um trabalho maior comparado à outra peça anônima, que diz assim, quando, e com que fundamentos? -assim como os sociólogos passam a perguntar por que a literatura popular de um período, o que as pessoas comuns realmente lêem, era de menos importância do que os textos canônicos. ${ }^{7 ”}$.

No fundo destas mudanças, percebemos a discussão então entre alta e baixa cultura, entre o espetáculo (como possível forma autêntica de cultura, as "salas de ópera", para lembrar o termo proposto por Roy Wagner (2010)) e o simulacro (no caso dos produtos culturais massificados, provindos da mídia, representações de representações), como aponta Santiago (2004); de onde emerge uma centralidade do pop na vida cotidiana contemporânea.

EM TESE BELO HORIZONTE $\quad$ v. $19 \quad$ N. $1 \quad$ JAN.-ABr. $2013 \quad$ ALBERTO. A centralidade do pop na mídia: 0 sujeito contemporâneo [...] $\quad$ P. 112-125


8. WIDDOWSON. Literature, p. 93.

9. WIDDOWSON. Literature, p 96.

10. WIDDOWSON. Literature, p. 96.

Mas como então pensar o pop na literatura? Como justificar a presença dele nas obras de Hornby e de que forma ele vai atuar como uma lógica de representação dos sujeitos na contemporaneidade? Pensando no embate entre as noções de sério e popular, alta e baixa cultura, protagonizadas por espécie de Literatura maiúscula, canonizada versus a abrangência textual que passa a ser analisada pós-anos 60 pelos Estudos Culturais, Widdowson vai propor traduzir o domínio ocupado pela literatura dentro da produção cultura como o "literário", um termo que serviria para entender os "discursos escritos que atuam em nossa sociedade, independentes de validações (nenhuma escrita seria mais literária que outra) e que abarque a diversidade da literatura, uma espécie de república das letras, cuja avaliação de um discurso textual é sempre provisória, variável e justificada por sua função".

A concepção para se justificar o "literário" seria então pensar que cada obra possui uma "autoconsciência, que a diferencia de outra, anunciando seu domínio"10, sendo o literário assim determinado pela eleição temática feita pelo autor pela competência de um leitor em reconhecê-la e por seu padrão literário interno (um poema possui sua "poemeza") - caberia então ao autor, ao leitor e à obra trabalharem na mesma chave, através, por exemplo, do que Culler chama de

convenções de leitura" que permitiriam leitores "descriminar, ler e criar sentido de obras literárias". ${ }^{11}$

11. WIDDOWSON. Literature, p. 98

\section{A POIÉSIS LITERÁRIA COMO POSSIBILIDADE DE} REPRESENTAÇÃO E RECONHECIMENTO

O que eu quero focar aqui é o fato de que a literatura, mesmo quando pretende ser uma forma de mimese realista, ou cópia da natureza ou representação da realidade, é na verdade "fazer", o que eu tenho chamado de realidades poiéticas. ${ }^{12}$

A etimologia da palavra poiésis (do grego poien) nos diz que ela se refere a fabricar ou produzir algo. Maturana e Varela, a partir deste conceito inicial, propõem um novo, a autopoiesis sugerindo que todo ser vivo atuaria como um sistema que se autoproduz de modo ininterrupto. A autopoiesis seria nosso equipamento sensorial, um sistema de reconhecimento do mundo e de reconhecimento de nós mesmos, já que "[...] vivemos com os outros seres vivos, e, portanto compartilhamos com eles o processo vital. Construímos o mundo em que vivemos durante as nossas vidas. Por sua vez ele também nos constrói ao longo dessa viagem comum". ${ }^{3}$

Ou seja, é nosso processo constante de interação, apontado pelos autores como uma dinâmica de dependência entre nosso mundo interno, nossa interpretação (innerwelt) com o externo, o espaço que nos reconhecemos como sujeitos
12. WIDDOWSON. Literature, p. 100: "What I want to focus on here is the fact that literature, even then rearistic mims to be a form nature" or "representing reality", is actually "making" what I have' is actually "making" what I have called poiet

13. MATURANA; VARELA. $A$ árvore do conhecimento, p. 10 
14. MATURANA; VARELA. $A$ árvore do conhecimento, p. 70.

15. MATURANA; VARELA. $A$ árvore do conhecimento, p. 215. (lebenswelt), de onde concluem que, portanto "todo fazer é conhecer". ${ }^{14}$

A autopoiesis atuaria como nosso processo interno de fabricação de conhecimento, a partir das trocas com o mundo exterior, explicitando nossa relação de autonomia (nos construímos internamente, a partir de nós mesmos) e dependência (nos construímos sempre a partir do outro), em um processo de interpretações que se constitui o que podemos chamar de subjetividade. É a relação sujeito/objeto: o que alguns semiólogos exemplificariam como a pedreza da pedra em que topamos o pé; ou o que Widdowson parece apontar como a "poemeza" de um poema, processos que constituem alguém sempre como sujeito e objeto em relação a algo. Se tomarmos a leitura de Castro (2012) a respeito da poiesis, como "o" vigorar da mediação como medida de tudo que é e não é sendo que o vigorar da medida denominou-se em grego logos. Sendo logos em uma tradução possível para o português, linguagem, esta atuaria como uma forma de autopoiesis, uma espécie de mediador e organizador do discurso, um sistema de reconhecimento que parece ser percebido por Maturana e Varela como "conduta cultural", ou a "estabilidade transgeracional de configurações comportamentais adquiridos ontogenicamente na dinâmica comunicativa de um meio social."15

Será que não poderíamos pensar essa dinâmica comunicativa como um repertório comum, ou como aponta Raymond Williams, "um padrão, uma 'estrutura de consciências' de um período no qual podemos experienciar as vivências particulares de todos os elementos na organização geral de uma comunidade, ou seja, sua cultura". ${ }^{16}$ Portanto, o fazer literário seria um tipo de trabalho que pode cumprir,

[...] objetivos societários do tipo mais profundo: não como alimento, abrigo ou ferramentas mas como "reconhecimentos"(marcas novas e confirmadoras) de pessoas e tipo de pessoas em lugares e tipos de lugares e, na verdade, muitas vezes mais ainda que isso, como "reconhecimentos" de uma espécie física em um universo físico compartilhado praticamente, com suas interações maravilhosamente diversas de sentidos, energias e potenciais. Interesse humano tão profundo - nos meios renovados e renováveis de reconhecimento, auto-reconhecimento e identidade - pode ser praticado numa gama muito extensa, das formas mais coletivas às mais individuais"17

E podemos pensar que o literário assume o papel de representar a "economia do restante da vida"18, como sugere Henry James, citado por Widdowson, oferecendo um mundo exterior editado, representando-o em algum tipo de direção, no que diz respeito a temas, sujeitos, etc. A ficção
16. WILLIAMS. The Long Revolution, p. 63: "By way of this perception of pattern, we can tap into the "structure of feeling" of a period, and experience "the particular living result of all the element in the general organization" of a community: that is, its culture". Tradução nossa.

17. WILLIAMS. Cultura, p. 128.

18. WIDDOWSON. Literature, p. 102. 
19. WIDDOWSON. Literature, p. 102.

20. ROBERT. Romance das origens, origens do romance, p. 18

21. WOOD. Como funciona a fiç̧ão p. 62 .

22. WIDDOWSON. Literature, p. 106

23. MATURANA; VARELA. $A$ árvore do conhecimento, p. 35-36 escolhe um tipo de recorte da vida, portanto, nos oferecendo uma "realidade estilizada perceptível e moldada em desenhos e padrões reconhecíveis" ${ }^{19}$, já que "o grau de realidade de um romance nunca é coisa mensurável, representando apenas a parcela de ilusão que o romancista deseja representar" ${ }^{20} \mathrm{Ou}$ como aponta Wood: "o artifício consiste na escolha do detalhe. Na vida podemos desviar os olhos e a cabeça, mas na verdade somos como câmeras impotentes. A lente é de grande abertura, e captamos tudo o que aparece. A memória seleciona, mas não do jeito que a narrativa literária seleciona"21 Ou seja, a autoconsciência do fazer literário que Widdowson aponta na verdade atuaria como uma realidade poiética no sentido de constituir e construir uma troca de informações, de conhecimentos, algo que representa, pela narrativa textual, a condição de nossas vidas cotidianas a partir da representação destas pela literatura - uma linguagem.

Ele parece exemplificar muito bem isso quando define que a lógica de representação realista nada mais é que “... encarnar o a-ser-conhecido como cognoscível”22 - ou, voltando a Maturana e Varella, a troca sugerida pelo literário seria a "ação que permita um ser vivo continuar sua existência em um determinado meio ao fazer surgir o seu mundo" ${ }^{23}$ Fazer, portanto, é também reconhecer o que está representado: estamos inscritos através da nossa subjetividade, em algum lugar.
Nossa compreensão do mundo é construída no discurso; somos formados e cúmplices no 'contar histórias'. Nossos sistemas de conhecimentos, significações e significados são todas narrativas textuais. É exatamente por isso que a textualização do 'real' no 'literário' é uma das razões prementes de porque a literatura continua sendo um recurso salutar para nós. ${ }^{24}$

A literatura atuaria como uma fonte de auto-pesquisa, de auto-conhecimento, auto-consciência, autopoiesis, portanto, cujas possibilidades de representação, estilizadas, oferecem sim um padrão, mas com a "[...] possibilidade de falar de uma comunidade conhecida, mas que pode ser conhecível em um novo sentido" 25 .

Será que a ficção hornbyana, portanto, não seria reconhecida no literário primeiramente, por sua inscrição no romance realista, e depois, por sua marca pop (seu pop-ness, sua popeza)? Talvez seja essa "autoconsciência", como propõe Widdowson, em relação ao pop, que ajude a inscrever tanto autor como a obra e o leitor em um processo de reconhecimento de tema e como ele é representado.

O que a literatura de Hornby parece estabelecer através de uma linguagem pop, é o que Williams apontaria como "padrões", Maturana e Varella como "conduta cultural” e Culler como "condições de leitura". O lebenswelt, o espaço da vida proposto por Hornby em suas obras - a conjunção do que
24. WIDDOWSON. Literature, p. 103.

25. WIDDOWSON. Literature, p. 105.
EM TESE
BELO HORIZONTE
v. 19
N. 1
JAN.-ABr. 2013
ALBERTO. A centralidade do pop na mídia: o sujeito contemporâneo [...]
P. $112-125$ 
26. HUYSSEN. Después de la gran división: Modernismo, cultura de masas, posmodernismo, p. 245

27. HUYSSEN. Después de la gran división: Modernismo, cultura de masas, posmodernismo, $\mathrm{p}$. 247: "Falta de valores y criterios en la crítica artística, y tenía la intención de salvar el vacío entre alta y baja cultura seria frívola". Tradução nossa.

28. HUYSSEN. Después de la gran división: Modernismo, cultur de masas, posmodernismo, p. 248. "El realismo del pop, súágeania con los objetos, imágenes y reproducciones de vida cotidiana, alentó un nuevo debate acerca de la relación entre el arte y la vida cotidiana, la imagen y la realidad, un debate que llenó las páginas de cultura de los diarios y semanarios nacionales". Tradução nossa. mapeamos como nosso e o que está lá fora, nossos processos de subjetivação - é cimentado pelo pop. O que não dispensa sua produção literária de ser organizada em certas formas genéricas, ou em uma forma de discurso bem demarcada.

\section{LITERATURA POP}

É importante pensar a respeito do pop na contemporaneidade, já que ele não parece assumir o mesmo papel e espaço que ocupou no início dos anos 60. Como aponta Huyssen o pop daquela década se "converteu em sinônimo de um novo estilo de vida da geração mais jovem, um estilo de vida que se rebelava contra a autoridade e aspirava libertar-se das normas impostas pela sociedade"26, o que ele aponta como uma "euforia emancipatória". Uma interpretação do pop menos como afirmação de uma sociedade capitalista que celebrava a si mesma e mais como um mecanismo de protesto e crítica. Segundo Huyssen, muitos alemães viam a pop-art como denunciadora de uma "falta de valores e de critérios na crítica artística, e que pretendia salvar o vazio entre a alta cultura séria e a baixa, frívola" ${ }^{27}$. Huyssen define que: "O realismo do pop, sua proximidade com objetos, imagens e reproduções da vida cotidiana, incentivou um novo debate sobre a relação entre arte e vida cotidiana, imagem e realidade, um debate que encheu as páginas de cultura dos diários e semanários nacionais". ${ }^{28}$
Parecia existir uma sensação de liberação, onde o pop formataria uma via de escape nestas noções de alta e baixa cultura e a idéia de arte (consumo e produção) seria expandida para outras esferas, além das torres de marfim ou dos acontecimentos exclusivos dos entendidos e marchands, percebida inclusive pela mídia. Ou seja: se a idéia de uma literatura pop anterior poderia apontar certas conexões contraculturais, já que a concepção de pop após a década de sessenta iria se referir também à cultura rock, ao hippismo, às drogas e, em geral, "a qualquer manifestação de uma sub-cultura ou do underground" ${ }^{29}$, hoje podemos perceber que o pop atua de forma mais centralizada, ocupando o papel que alguns autores chamariam mainstream, espécie de fluxo principal de localização da cultura de massas.

A obra de Hornby então pode ser percebida como síntese de uma possível literatura pop contemporânea, no entendimento de que a cultura midiática e mundializada de hoje atua não apenas como elemento narrativo, mas de certa forma, como um personagem de suas histórias e contribui, como afirma Serelle, "para a percepção de uma ótica midiática onipresente, global, que atua como moduladora das subjetividades e das interações entre os sujeitos" ${ }^{30}$. Portanto, é possível pensar que a idéia de literatura pop ganha outra conotação no fazer literário contemporâneo.
29. HUYSSEN. Después de la gran división: Modernismo, cultura de masas, posmodernismo, p. 245: "Cualquier manifestación de una subcultura y lo subterráneo". Tradução nossa.

30. SERELLE. Sujeito e vida midiatizada: considerações sobre a ficção de Nick Hornby, p. 134.

EM TESE $\quad$ BELO HORIZONTE $\quad$ V. $19 \quad$ N. $1 \quad$ JAN.-ABR. $2013 \quad$ ALBERTO. A centralidade do pop na mídia: 0 sujeito contemporâneo [...] $\quad$ P. 112-125


31. CRUZ. O pop: literatura, mídia e outras artes, p. 44.

32. CRUZ. O pop: literatura, mídia e outras artes, p. 35.

33. CÂNDIDO apud SANTIAGO. O cosmopolitismo do pobre, p. 127.

34. CRUZ. O pop: literatura, mídia e outras artes, p. 45.

\section{UMA DIMENSÃO CONTEMPORÂNEA DO POP NA}

LITERATURA

Cruz questiona se é possível pensar a literatura pop a partir da década de 1960 como uma leitura das experiências com o pop no campo das artes plásticas, através de uma transposição "[...] da linguagem visual iconográfica para a linguagem verbal, ressaltando-se a antiga relação entre a literatura e as artes plásticas na qual se moldou a estética tradicional para a classificação dos movimentos estilísticos da arte ocidental"31. Justificando essa possibilidade, ele alinha apropriações possíveis que a literatura pop fez da arte pop: a temática, a técnica, os mitos e a linguagem.

Traçando paralelos, é possível perceber na obra de Hornby com nitidez, pelo menos três destas questões apontadas por Cruz como sinalizadoras de uma literatura pop. A temática focada em elementos da cultura de entretenimento como a música, o cinema, a TV, etc.; a técnica, através de, por exemplo, a superposição de imagens e colagens; e os mitos, referentes ao que Cruz aponta como "mitos urbanos criados e difundidos pela mídia" 32 , que nos remete ao "... folclore urbano que é a cultura massificada". ${ }^{33}$

O último ponto de convergência entre arte pop e literatura pop seria a linguagem, como ele situa, "[...] a insubordinação às regras, a busca de novas formas, o discurso do sonho e do inconsciente, a carnavalização"34. Ou seja, Cruz parece atentar que uma linguagem pop seria possível ao se submeter às possibilidades de desconstruções textuais típicas, por exemplo, das teorias literárias estruturalistas, bakhtinianas ou pós-modernistas, que prezam pela opacidade textual.

Assim veremos como a literatura pop se utiliza dos mitos urbanos criados e difundidos pela mídia para investigar o interior da estrutura capitalista e revelar suas intenções de monopólio, poder e controle através da indústria cultural, estabelecendo a sua análise e crítica da modernidade a partir da Revolução Industrial. Ao mesmo tempo em que questiona a tradição artística, a literatura pop propõe um novo modelo estético e desestrutura as formas da narrativa tradicional. ${ }^{35}$

Mas Hornby garante não estar "particularmente interessado na linguagem" (2006, p. 4), ou seja, ele parece pensar a linguagem no "que" se descreve, e não no "como" se descreve. Sua obra se inscreve na chave do romance, mas sem maiores tentativas de desordenar as possibilidades de escrita como sugerem outras possíveis teorias literárias, aplicadas especialmente no pós-modernismo. Não parece interessar ao autor a opacidade, e sim a transparência realista; ao mesmo tempo que não se vê na obra hornbyana mecanismos de argumentação crítica em relação à idéia de indústria cultural: pelo contrário, ela parece se filiar, se assumir com fruto desta, mesmo que a partir disso possa moldar um retrato
35. CRUZ. O pop: literatura, mídia e outras artes, p. 35.
EM TESE
BELO HORIZONTE
v. 19
N. 1
JAN.-ABR. 2013
ALBERTO. A centralidade do pop na mídia: o sujeito contemporâneo [...]
P. $112-125$ 
36. ROBERT. Romance das origens, origens do romance, p. 27.

37. “Después de la gran division” (2002) é o título do livro de Andreas Huyssen e seu conceit central, onde ele teoriza sobre a separação entre alta e baix cultura no século XX e seu possivel marco para uma separação entre o modernismo e o pós-modernismo. geracional auto-irônico, especialmente nos personagens adultos mas "eternamente jovens" e viciados em cultura pop de suas obras.

Talvez esteja aí o ponto de tensionamento entre uma literatura pop aos moldes do que sugere Cruz (a partir de obras literárias dos anos 60 e 70) e o que percebemos na obra de Hornby: sua ficção reivindica um tipo de transparência que o filiaria ao gênero de romance realista, onde, como define Robert, "a verdade do romance não reside em outra coisa senão em um aumento de seu poder de ilusão"36; de onde o romance (e não a linguagem) sobrevive do "como se" embora queira justamente fazê-lo esquecer, através de artificialidades que se parecem naturais. E a idéia de realismo em Hornby é embalada em fartas referências pop, como se a centralidade do pop na vida cotidiana contemporânea fosse indispensável para construir essa noção exata do que é real.

Se ambas as possibilidades de escrita pop estão situadas "depois da grande divisão" 37 , para usar a expressão de Huyssen, em Hornby é perceptível uma outra dimensão do pop, que evidentemente não se filia à opacidade de linguagem apontada por Cruz (2003): a dos filmes, séries televisivas, canções que são, via de regra, transparentes, imediatas e consumíveis. Essa dimensão tanto antecede a pop art como a procede, talvez, após a valorização destes objetos no campo das artes plásticas, de forma menos envergonhada pelo seu caráter imediato - ainda que a vontade de separação entre alta e baixa cultura persista em determinadas óticas (e possivelmente a literária é uma delas). Desse ponto de vista, Hornby é transparente, filia-se ao romanesco, aos costumes, ao ordinário midiático de seu tempo, à cultura dessa segunda (que também foi a primeira) dimensão do pop. Refletindo-a e constituindo-a, Hornby se insere através de sua popeza, apontando, aqui e ali, uma aresta, um desconforto, que também pode ser notada como citado um autorretrato irônico de sua ficção.

É a partir desta auto-consciência, portanto, que ele cria então uma condição de leitura no qual seus personagens dialogam com o leitor de acordo com alguns padrões estabelecidos pelo pop. A navegação mais completa pelos romances de Hornby passa por entender que a obsessão que alguém cultiva por determinada peça cultural (um livro, um filme, um músico), que se confunde muitas vezes com a própria vida - no sentido de que vai além da fruição estética e consegue atuar como agente modulador de subjetividades do sujeito.

Através do suporte do romance - uma forma clássica de se contar histórias - o autor vai trabalhar o tempo todo de olho no presente, uma espécie de atualização do realismo literário do século XIX, sendo o inventário atual (o que nos leva ao thingsm apontado por Brooks ${ }^{38}$ ) constituído pelas coisas dispostas e disponíveis em uma sociedade onde a mídia e o pop
38. A acumulação de informações da qual a linguagem pop se torma possibilita uma conexão Realismo Literário do século XIX apontados por Brooks (2005). Um delos é Broks (2005).

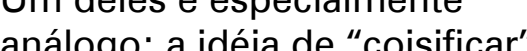
(thing-ism) tratar os objetos do (thing-ism) tratar os objetos do mundo como um inventario realidade à narrativa. (BROOKS, 2005 p. 16) já que o (BuO 2005 p. 16), já que o autor aponta que não é possivel representar as pessoas (e o "coisdo) sem mencionar as coisas" que elas adquirem para se definirem como sujeitos.

EM TESE $\quad$ BELO HORIZONTE $\quad$ V. $19 \quad$ N. $1 \quad$ JAN.-ABR. $2013 \quad$ ALBERTO. A centralidade do pop na mídia: 0 sujeito contemporâneo [...] $\quad$ P. 112-125


parecem hegemonizar o cenário. E a literatura de Hornby assume o diálogo mais imediato com o contemporâneo, afirmando que sua ótica literária não pode ser contrária ao pop e inadaptável aos acontecimentos recorrentes da cultura midiática.

Em grande parte de sua obra, o pop atua não apenas como um elemento casual que aparece furtivamente como descrição de um ou outro personagem, funcionando genericamente como indicações de consumo - o pop para Hornby atua como a grande temática e técnica em seus livros, na overdose de citações intertextuais, metáforas e metonímias provindas de canções, citações a filmes, etc. A partir desta estrutura, ele cria então uma condição de leitura onde seus personagens dialogam com o leitor de acordo com alguns padrões estabelecidos pelo pop: dificilmente o leitor vai compreender profundamente personagens como Rob Fleming (Alta Fidelidade, 1998) ou Duncan (Juliet Nua e Crua, 2010) sem estar familiarizado com a cartografia pop montada para composição destes personagens. Como aponta Santiago:

[...] os próprios artistas estão investindo a sua imaginação criadora em novos e outros campos, isto é, estão descobrindo novos modos de ler uma produção cultural que não se manifesta pela escrita, como a indicar que existe na disseminação massificada de simulacros um universo a ser investigado para que se tenha uma visão do mundo que finquem seu pé na atualidade. Eles estão como que a dizer aos seus leitores: vejam como eu tive de aperfeiçoar outras formas de leitura para ser contemporâneo, porque vocês não tentam também? Há que se ter menos preconceito para com as formas pop de produção artista. $^{39}$

\section{HORNBY E O SUJEITO CONTEMPORÂNEO}

[...] pareceu óbvio que a cultura pop era uma parte importante de nossas vidas, e que deveria existir algum tipo de reflexão sobre ela nos livros que lemos. Eu nunca entendi o porquê das pessoas não descreverem ou apenas mencionarem os programas de TV que elas estavam assistindo. Eu sempre suspeitei que fosse algo que tem a ver com ter um olho na posteridade. ${ }^{40}$

Silviano Santiago (2004) traça paralelos sobre a literatura e a cultura de massas, recuperando a leitura benjaminiana a respeito do cinema lembrando que, sob esta lógica, se "o filme não exterioriza o tempo e o gosto contemporâneos e não mantêm um diálogo imediato e eficaz com os expectadores está fadado ao fracasso ou à inexistência" ${ }^{41}$, como forma de ratificar a força do consumo atual. Mas o que interessa aqui não é o pop apenas como potência de consumo, e sim como ele está ligado a uma idéia de "tempo presente", de algo que "... independente de qualquer especificidade discursiva fosse
39. SANTIAGO. O cosmopolitismo do pobre, p. 130.

40. HORNBY. The Complete Polysyllabic Spree: The Diary of an Occasionally Exasperated But Ever Hopeful Reader.

41. SANTIAGO. O cosmopolitismo do pobre, p. 113. 
42. SANTIAGO. O cosmopolitismo do pobre, p. 115

43. HORNBY. Alta fidelidade, p. 28. entregue ao consumidor contemporâneo na sua contemporaneidade". ${ }^{42}$ É possível, portanto, de alguma forma alinhar a linha de pensamento de Hornby com este estatuto. Ele narra o aqui e agora, é esse o seu foco, que se traduz inclusive nas descrições de seus romances.

Em uma frase do personagem Rob Fleming, de Alta Fidelidade (1998), parece estar uma das chaves para entender parte da questão sugerida por Hornby: "O que veio primeiro, a música ou a dor? Eu ouvia música porque estava infeliz? Ou estava infeliz porque ouvia música? Esses discos todos transformam você numa pessoa melancólica? [...] As pessoas mais infelizes que conheço são as que mais gostam de música pop. $" 43$

A música pop atua como moduladora da subjetividade do personagem: parece impossível para ele separar seu self do pop. O personagem, dono de uma loja de discos mal sucedida comercialmente, passa boa parte de seu tempo com dois outros funcionários elencando e ranqueando artigos do pop especialmente da música, em um exercício que mescla memória afetiva, julgamento crítico e irônico, que vai além da idéia de preferência pessoal a respeito de artigos culturais e fomenta a própria construção do seu "eu", onde o sujeito fala através de outros. Em Juliet Nua e Crua, com o personagem Duncan Mitchel, Hornby parece radicalizar essa proposta, descrevendo-o assim:
Ele era especialista em cinema independente americano dos anos setenta e em romances de Nathaniel West, e estava desenvolvendo uma bela linha nova nos seriados televisivos do HBO (achava que estaria pronto para ensinar The Wire num futuro não muito distante). Por comparação, porém, essas coisas não passavam de namoricos. Tucker Crowe era o seu parceiro de vida. Se Crowe morresse (morresse na vida real, ou seja, não apenas criativamente), Duncan seria o primeiro a vestir o luto ${ }^{44}$.

Tanto em Alta Fidelidade quanto em Juliet Nua e Crua o sujeito se reconhece e é representado por outros, uma espécie de voz pop que articula suas ações e particularidades, e através desta, busca uma espécie de singularização, já que o seu pop não é o mesmo de outros. Os caminhos encontrados, em ambos os casos, para buscar essa diferenciação, passam pela visão crítica imbuída nos personagens, como se apenas o conhecimento enciclopédico e o envolvimento profundo com a música pop autorizasse alguém a falar por e em nome dela. No caso de Alta Fidelidade, nota-se que os personagens assumem o papel de guardiões do pop que vale a pena - um comprador deseja um disco de Stevie Wonder e é espantado da loja por supostamente ofender os funcionários com seu "gosto horroroso"45 (1998, p. 52) como se eles realmente fossem os autênticos juízes do gosto, um papel desde sempre assumido pelos críticos culturais. Em Juliet nua e crua,
44. HORNBY. Juliet nua e crua, p. 12.

45. HORNBY. Alta fidelidade, p. 52.
EM TESE
BELO HORIZONTE
v. 19
N. 1
JAN-ABR. 2013
ALBERTO. A centralidade do pop na mídia: o sujjeito contemporâneo [...]
p. $112-125$ 
46. HORNBY. Juliet nua e crua, p. 47. um dos momentos de maior intensidade dramática é quando Annie, a esposa de Duncan escreve uma resenha sobre um álbum do artista favorito do marido, para uma comunidade especializada na Internet, e percebe que, de alguma forma tal álbum lhe dera " [...] ideias sobre arte, trabalho, seu relacionamento, o relacionamento de Tucker, o apelo misterioso do obscuro, homens e música, o valor do coro em uma canção, o propósito da harmonia e a necessidade de ambição." 46 Elencam-se critérios relativos a uma possível crítica musical (harmonia, coros) com a percepção nítida de que a análise da música, na realidade, a leva a pensar em sua própria subjetividade (o obscuro, a ambição).

Essa relação entre reconhecimento dos personagens com o pop, e sua representação através do pop, é substrato fundamental na composição narrativa de Hornby: sua literatura é farta de exemplos nesse sentido. A julgar pelo restante de sua bibliografia, podemos acreditar que parte de seu desafio como romancista foi justamente o de tentar "botar as coisas pra fora”, pensar a capacidade não apenas da música, mas do cinema, das séries televisivas e da literatura de nos decodificar, de forma verbal, textual, imagética, através de uma linguagem pop. Com suas narrativas que ele parece tentar devolver o que nos afeta internamente - a atuação do que vem de fora, nesta cultura midiatizada, sobre nós. E através do suporte do romance - uma forma clássica de se contar histórias - o autor vai trabalhar o tempo todo de olho no presente, uma espécie de atualização do realismo literário do século XIX, sendo o inventário atual as coisas dispostas e disponíveis em uma sociedade onde a mídia e o pop parecem hegemonizar o cenário. Portanto, a literatura de Hornby parece querer se assumir como um espelho do contemporâneo, tomando esse papel afirmando que em sua ótica literária não pode ser contrária ao pop e inadaptável aos acontecimentos recorrentes da cultura midiática.

\section{REFERÊNCIAS}

BROOKS, Peter. Realist Vision. New Haven: Yale University Press, 2005.

CASTRO, Manuel Antônio de e outros. Dicionário de Poética e Pensamento. Internet. Disponível em: http://www.dicpoetica. letras.ufrj.br. Acesso em 15 de novembro, 2012.

CRUZ, Décio Torres. O pop: literatura, mídia e outras artes. Salvador: Quarteto, 2003.

HORNBY, Nick. Alta Fidelidade. Rio De Janeiro: Rocco, 1998.

Juliet Nua e Crua. Rio De Janeiro: Rocco, 2010

Nick Hornby's official site, Internet. Disponível em http://www.penguin.co.uk/static/cs/uk/0/minisites/nickhornby/ aboutnick/index.html. Acesso em 12 de novembro de 2011. (a) 
The Complete Polysyllabic Spree: The Diary of an Occasionally Exasperated But Ever Hopeful Reader. Internet. Disponível em http://www.guardian.co.uk/books/2006/oct/14/ referenceandlanguages.nickhornby. Acesso em 12 de novembro de 2011. (b)

HUYSSEN, Andreas. Después de la gran división: Modernismo, cultura de masas, posmodernismo. Buenos Aires: Adriana Hidalgo Editora, 2002

KELLNER, Douglas. A cultura da mídia. Bauru: Edusc, 2001

MATURANA, Humberto \& Varela, Francisco. A árvore do conhecimento. Campinas: Editorial Psy II, 1995

PARSONS, Tony. Disparos no front da cultura pop. São Paulo: Barracuda, 2005.

ROBERT, Marthe. Romance das origens, origens do romance São Paulo, Cosac Naif, 2007

SANTIAGO, Silviano. $\mathbf{O}$ cosmopolitismo do pobre. Belo Horizonte: Editora UFMG, 2004

SERELLE, Márcio. Sujeito e vida midiatizada: considerações sobre a ficção de Nick Hornby. Revista Famecos: mídia, cultura e tecnologia, Vol. 1, No 38, 2009

WAGNER, Roy. A invenção da Cultura. São Paulo: Cosac \& Naify, 2010

WILLIAMS, Raymond. Cultura. Rio de Janeiro: Paz e Terra, 1992.
WILLIAMS, Raymond. The Long Revolution. Harmondsworth: Penguin Books, 1971.

WIDDOWSON, Peter. Literature. Londres: Routledge, 1999

WOOD, James. Como funciona a ficção. São Paulo: Cosac Naif, 2011 